\title{
Synthesis of Vitamin B6 by a Mutant of Escherichia coli K12 and the Action of $4^{\prime}$-Deoxypyridoxine
}

\author{
By THOMAS A. SCOTT AND ROBERT C. HOCKNEY* \\ Department of Biochemistry, University of Leeds, 9 Hyde Terrace, \\ Leeds LS2 9LS
}

(Received 30 May 1978; revised 16 August 1978)

\begin{abstract}
Mutants of Escherichia coli $\mathrm{K} 12$ blocked in the oxidation of pyridoxine 5'-phosphate ('Oxidase' mutants) excreted pyridoxine at an initial rate of $19 \mathrm{pmol} \mathrm{h}^{-1}\left(10^{8} \text { bacteria }\right)^{-1}$, i.e. $0.6 \mathrm{nmol} \mathrm{h}^{-1}$ (mg dry wt) ${ }^{-1}$, when starved for pyridoxal. Glycolaldehyde, L-phosphoserine, DL-serine and, to a lesser extent, L-leucine stimulated the rate of pyridoxine excretion, but there was no significant stimulation by 2 '-hydroxypyridoxine. $4^{\prime}$-Deoxypyridoxine inhibited or stimulated growth of the 'Oxidase' mutant, depending on the relative concentrations of added pyridoxal and 4'-deoxypyridoxine. It was concluded that stimulation of growth by $4^{\prime}$-deoxypyridoxine was due to its conversion to pyridoxal.
\end{abstract}

\section{INTRODUCTION}

The only known intermediate of vitamin B6 biosynthesis in plants and bacteria is pyridoxine 5 '-phosphate, which is oxidized to the active coenzyme pyridoxal 5'-phosphate (Dempsey, 1966). In the course of characterization of $p d x$ mutations in Escherichia coli K12, we found that mutants blocked in the conversion of pyridoxine $5^{\prime}$-phosphate to pyridoxal 5 '-phosphate ('Oxidase' mutants) could cross-feed mutants blocked at an earlier stage of vitamin B6 synthesis (Hockney \& Scott, 1979). It was of interest to determine whether the excreted material responsible for the cross-feeding was pyridoxine $5^{\prime}$-phosphate or a derivative, possibly pyridoxine. Since the extent of excretion of this precursor was easily measurable by microbiological assay, it suggested a rapid and economical method for screening compounds for their ability to promote or inhibit vitamin B6 biosynthesis.

The vitamin B6 analogue 4'-deoxypyridoxine has been reported to inhibit the growth only of organisms that cannot synthesize vitamin B6, when the external supply of the vitamin is limiting (Rabinowitz \& Snell, 1953). Recently, however, 4'-deoxypyridoxine at a concentration of $10 \mathrm{mg} \mathrm{ml}^{-1}$ was reported to cause $22 \%$ inhibition of the growth of Flavobacterium devorans which is prototrophic for vitamin B6 (Picton, 1975).

The present work describes the identification of the pyridoxal 5 '-phosphate precursor excreted by an 'Oxidase' mutant, the effect of various compounds on this excretion, and the effect of 4'-deoxypyridoxine on both the 'Oxidase' mutant and its parent strain.

\section{METHODS}

Organisms, growth and vitamin B6 production. Escherichia coli $\mathrm{K} 12$ 'Oxidase' mutant BL-1 and its parent E. coli K12 CR63, described by Hockney \& Scott (1979), were used. Strain BL-1 was grown in the glucose/ salts (G/S) medium of Davis \& Mingioli (1950) supplemented with $120 \mathrm{ng}$ pyridoxal ml-1, at $37^{\circ} \mathrm{C}$ with shaking. Bacteria were harvested by centrifuging during exponential growth $\left(5 \times 10^{8}\right.$ bacteria $\left.\mathrm{ml}^{-1}\right)$. After resuspension at the same concentration in $\mathrm{G} / \mathrm{S}$ medium, with (test) or without (control) the compound under investigation, the cultures were incubated with shaking for $3 \mathrm{~h}$ at $37^{\circ} \mathrm{C} . A_{540}$ was determined at intervals

* Present address: Research Laboratories, Bass Production Ltd, High Street, Burton-on-Trent DE14 1JZ. 
and after $3 \mathrm{~h}$ the pyridoxine concentration of the medium was determined by microbiological assay (Hockney \& Scott, 1979).

Identification of vitamin B6 compounds. The column chromatographic technique of Tiselius (1972) using Dowex $50\left(\mathrm{H}^{+}\right.$form $)$with a combined $\mathrm{pH}$ and concentration gradient of ammonium formate separates all the vitamin E6 compounds. This method was used to identify vitamin B6 compounds of microbiological origin as described by Scott \& Picton(1976). The 'Oxidase' mutant BL-1 was harvested by centrifuging during exponential growth and resuspended at the same density in G/S medium without vitamin B6 supplement. After incubation for $3 \mathrm{~h}$ at $37^{\circ} \mathrm{C}$, the bacteria were removed by centrifuging and the supernatant was assayed for vitamin B6 compounds (Scott \& Picton, 1976).

Uptake of pyridoxine by E. coli CR63. The uptake of pyridoxine by E. coli CR63 was determined with [G- ${ }^{3} \mathrm{H}$ ]pyridoxine (The Radiochemical Centre, Amersham). G/S medium $\left(50 \mathrm{ml}\right.$ ) containing $150 \mathrm{ng}\left[\mathrm{G}-{ }^{3} \mathrm{H}\right]-$ pyridoxine $\mathrm{ml}^{-1}$ (specific activity $0.24 \mathrm{Ci} \mathrm{mmol}^{-1}$ ) and $6.0 \mathrm{mg}^{\prime} 4^{\prime}$-deoxypyridoxine $\mathrm{ml}^{-1}$ was inoculated with E. coli $\mathrm{CR} 63$ to a density of $5 \times 10^{7}$ bacteria $\mathrm{ml}^{-1}$. A control culture without $4^{\prime}$-deoxypyridoxine was similarly prepared. Both cultures were incubated with shaking at $37{ }^{\circ} \mathrm{C}$ for $6 \mathrm{~h}$ and $A_{540}$ was measured at intervals Uptake of $\left[\mathrm{G}-{ }^{3} \mathrm{H}\right]$ pyridoxine was determined (Scott \& Picton, 1976) after collecting and washing the cells on membrane filters (Oxoid $25 \mathrm{~mm}, 0.45 \mu \mathrm{m}$ pore size).

Vitamin $\mathrm{B} 6$ compounds in cultures after incubation in the presence of 4'-deoxypyridoxine. The 'Oxidase' mutant BL-1 was incubated in $80 \mathrm{ml} \mathrm{G} / \mathrm{S}$ medium supplemented with $120 \mathrm{ng}$ pyridoxal ml ${ }^{-1}$ until there were $5 \times 10^{8}$ bacteria $\mathrm{ml}^{-1}$. The organisms were collected by centrifuging and divided equally between $40 \mathrm{ml} \mathrm{G} / \mathrm{S}$ medium and $40 \mathrm{ml} \mathrm{G} / \mathrm{S}$ medium containing $2.0 \mathrm{mg} 4^{\prime}$-deoxypyridoxine $\mathrm{ml}^{-1}$. After $3 \mathrm{~h}$ at $37^{\circ} \mathrm{C}$, the cultures were made $0.05 \mathrm{M}$ with respect to $\mathrm{H}_{2} \mathrm{SO}_{4}$ and heated at $121{ }^{\circ} \mathrm{C}$ for $3 \mathrm{~h}$. This treatment hydrolysed the phosphates of vitamin B6 compounds into the non-phosphorylated derivatives. (The microbiological assay organism, Kloeckera apiculata, does not respond to phosphorylated vitamin B6 compounds.) Insoluble debris was removed by centrifuging and the supernatant was analysed for vitamin B6 compounds (Scott $\&$ Picton, 1976). Direct microbiological assay of the hydrolysed culture was not possible owing to the presence of the inhibitor 4'-deoxypyridoxine, but this was separated from the other vitamin B6 compounds by the column chromatography

\section{RESULTS}

Excretion of vitamin B6. When strain BL-1 was starved for pyridoxal, vitamin B6 (subsequently shown to be entirely pyridoxine) was excreted into the medium at 19 pmol $\left(10^{8} \text { bacteria }\right)^{-1}$ during the first hour. Bacteria continued to excrete pyridoxine after $3 \mathrm{~h}$, but the rate of excretion progressively decreased. The total pyridoxine excreted after $3 \mathrm{~h}$ was $38 \mathrm{pmol}\left(10^{8} \text { bacteria }\right)^{-1}$. The total vitamin B6 measured microbiologically in the culture supernatant could be accounted for by the pyridoxine detected chromatographically. Similar quantities of vitamin B6 were detected after the culture or the effluent from the analytical column had been hydrolysed. Significant quantities of other vitamin B6 compounds were not detected.

Pyridoxine production in supplemented $G / S$ medium. The effect of adding various compounds to the $\mathrm{G} / \mathrm{S}$ medium on the production of pyridoxine by strain BL-1 is shown in Table 1.

Growth of strain BL-1 and its parent CR63 in the presence of $4^{\prime}$-deoxypyridoxine. The rate of growth and final bacterial density of $E$. coli CR63 decreased when 4'-deoxypyridoxine was added to the $\mathrm{G} / \mathrm{S}$ medium. In the range 0 to $10 \mathrm{mg} 4^{\prime}$-deoxypyridoxine $\mathrm{ml}^{-1}$, the inhibition of growth rate was directly proportional to the concentration of inhibitor; $50 \%$ inhibition was achieved with a concentration of $6.0 \mathrm{mg} 4^{\prime}$-deoxypyridoxine $\mathrm{ml}^{-1}$. Similar results were obtained when the 'Oxidase' mutant BL-1 was grown in G/S medium supplemented with excess pyridoxal $\left(120 \mathrm{ng} \mathrm{ml}^{-1}\right) ; 50 \%$ inhibition was observed at a concentration of $6.7 \mathrm{mg} \mathrm{4}$-deoxypyridoxine $\mathrm{ml}^{-1}$. With $6.0 \mathrm{ng}$ pyridoxal $\mathrm{ml}^{-1}$, which is growth-limiting for BL-1, both the growth rate and the final bacterial density were either stimulated or inhibited by $4^{\prime}$-deoxypyridoxine depending on its concentration. The greatest stimulation

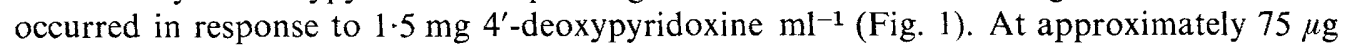
$4^{\prime}$-deoxypyridoxine $\mathrm{ml}^{-1}$, the effects of growth inhibition and stimulation appeared to be balanced, and growth was the same as in the absence of 4 -deoxypyridoxine. At lower concentrations, growth was inhibited, the maximum inhibition being $50 \%$ caused by an inhibitor concentration of $5 \mu \mathrm{g} \mathrm{ml}^{-1}$. 
Table 1. Effect of various compounds on the excretion of pyridoxine by the

$$
\text { E. coli 'Oxidase' mutant BL-1 }
$$

Strain BL-1 was grown in G/S medium supplemented with $120 \mathrm{ng}$ pyridoxal $\mathrm{ml}^{-1}$, at $37^{\circ} \mathrm{C}$. Bacteria were harvested during exponential growth $\left(5 \times 10^{8}\right.$ bacteria $\left.\mathrm{ml}^{-1}\right)$ and resuspended in $\mathrm{G} / \mathrm{S}$ medium supplemented with different compounds as shown. After $3 \mathrm{~h}$ at $37^{\circ} \mathrm{C}$ the bacterial density and the concentration of pyridoxine excreted into the medium were determined. The results show pyridoxine excretion [pmol $\left(10^{8} \text { bacteria }\right)^{-1}$ ] as a percentage of the total pyridoxine excreted in $3 \mathrm{~h}$ by strain BL-1 in the absence of added compounds $\left[38 \mathrm{pmol}\left(10^{8} \text { bacteria }\right)^{-1}\right.$ ]. Unless stated otherwise, each compound was added at $0.4 \mathrm{~mm}$.

\section{Compound added to $\mathrm{G} / \mathrm{S}$ medium}

L-Alanine
D-Alanine
$\beta$-Alanine
Dihydroxyacetone phosphate
D-Fructose
Glyceraldehyde
D-Glucose $(40 \mathrm{~mm})$
Glycolaldehyde
Glycerol
L-Glutamate
L-Glutamine
L-Histidine
L-Leucine

$$
\begin{gathered}
\text { Pyridoxine } \\
\text { excretion } \\
(\% \text { of control) }
\end{gathered}
$$

96

108

110

101

95

106

113

173

101

114

93

79

149

\section{Compound added to} $\mathrm{G} / \mathrm{S}$ medium

Malonate (10 mM)

D-Pantothenate

L-Phosphoserine $(6 \mu \mathrm{M})$

L-Phosphoserine

Pyruvate

DL-Serine $(12 \mu \mathrm{M})$

DL-Serine

DL-Serine (20 mM)

D-Xylulose

2'-Hydroxypyridoxine

Glycolaldehyde $(0.4 \mathrm{~mm})+$ DL-Serine $(0 \cdot 8 \mathrm{~mm})$

$$
\begin{gathered}
\text { Pyridoxine } \\
\text { excretion } \\
\text { (\% of control) }
\end{gathered}
$$

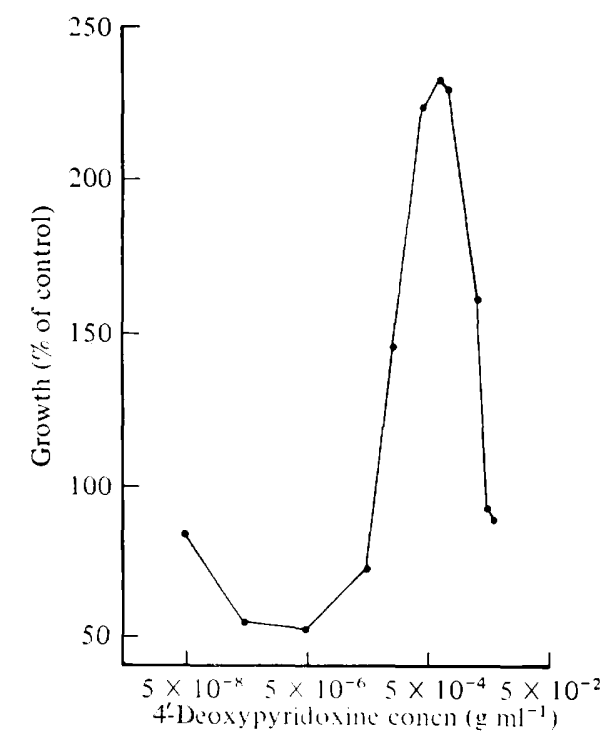

Fig. 1. Growth of the 'Oxidase' mutant BL-1 in the presence of different concentrations of $4^{\prime}$-deoxypyridoxine. Bacteria were grown in $\mathrm{G} / \mathrm{S}$ medium supplemented with $6.0 \mathrm{ng}$ pyridoxal $\mathrm{ml}^{-1}$ and $4^{\prime}$-deoxypyridoxine at the concentrations shown. Cultures were incubated at $37^{\circ} \mathrm{C}$ with shaking. The final density of each culture was expressed as a percentage of the density of a control culture containing no $4^{\prime}$-deoxypyridoxine. Each culture started at $5 \cdot 0 \times 10^{5}$ bacteria $\mathrm{ml}^{-1}$, and the final density of the control culture was $2 \cdot 2 \times 10^{6}$ bacteria $\mathrm{ml}^{-1}$.

Uptake of pyridoxine by strain CR63. The presence of $6.0 \mathrm{mg} 4^{\prime}$-deoxypyridoxine $\mathrm{ml}^{-1}$ abolished the uptake of $\left[\mathrm{G}-{ }^{3} \mathrm{H}\right]$ pyridoxine by strain $\mathrm{CR} 63$. In the absence of $4^{\prime}$-deoxypyridoxine the rate of uptake of pyridoxine was approximately $3 \mathrm{pmol} \mathrm{h}^{-1}\left(10^{6} \text { bacteria }\right)^{-1}$ during exponential growth. 
Vitamin $\mathrm{B} 6$ compounds in cultures of E. coli BL-1 after incubation in the presence of $4^{\prime}$-deoxypyridoxine. Cultures of strain BL-1 $\left(2 \times 10^{10}\right.$ bacteria in $\left.40 \mathrm{ml}\right)$ contained $129 \mathrm{ng}$ and $79 \mathrm{ng}$ pyridoxal after incubation with or without $2.0 \mathrm{mg} \mathrm{4}$-deoxypyridoxine $\mathrm{ml}^{-1}$, respectively. The extent to which the pyridoxal was free or present as pyridoxal $5^{\prime}$-phosphate is not known because the cultures were hydrolysed before analysis. Each culture also contained large quantities of pyridoxine and traces of pyridoxic acid. Analysis for pyridoxamine was not performed.

\section{DISCUSSION}

Although pyridoxine 5'-phosphate is the immediate precursor of pyridoxal 5'-phosphate in $E$. coli, it is not surprising to find that an organism unable to catalyse this conversion excretes pyridoxine. A pyridoxine phosphate oxidase mutant of $E$. coli B was reported to excrete both pyridoxine and pyridoxine $5^{\prime}$-phosphate (Dempsey, 1966). It is assumed that 'Oxidase' mutants of E. coli $\mathrm{K} 12$ also tend to accumulate metabolically useless pyridoxine 5 -phosphate within the cell. Thus pyridoxine 5'-phosphate may be excreted with partial (E. coli $\mathrm{B})$ or total $(E$. coli $\mathrm{K} 12)$ dephosphorylation.

In the absence of pyridoxal, the 'Oxidase' mutant BL-1 cannot grow and synthesizes pyridoxine at a rate about three times that of the wild-type strain (Hockney \& Scott, 1979), possibly due to relief from feedback inhibition by pyridoxal $5^{\prime}$-phosphate. Most of this pyridoxine is excreted, and any compound that stimulates the excretion of pyridoxine probably exerts its effect by stimulating the pathway of vitamin B6 biosynthesis.

A scheme for the biosynthesis of vitamin B6, involving glycolaldehyde, xylulose and 2'hydroxypyridoxine has been proposed by Schroer \& Frieden (1973). This scheme predicts that

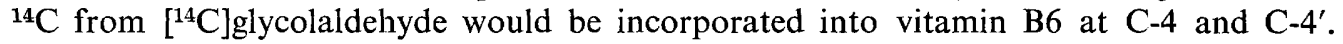
Radiotracer experiments have shown, however, that the aldehyde and alcohol carbon atoms of glycolaldehyde are incorporated into C-5 and C-5' respectively (Hill et al., 1975). Data in Table 1 support the role of glycolaldehyde in vitamin B6 biosynthesis but give no support to the role of xylulose or 2 '-hydroxypyridoxine. The possibility that the stimulation of pyridoxine synthesis by glycolaldehyde was due to its conversion into serine was eliminated by the demonstration of additivity of stimulation with glycolaldehyde and a saturating concentration of serine. Phosphoserine has been suggested as a precursor of vitamin B6 (Dempsey, 1969) because strains unable to dephosphorylate it synthesize vitamin B6 at an elevated rate; our present results support this suggestion Since the extracellular alkaline phosphatase of $E$. coli is repressed in $\mathrm{G} / \mathrm{S}$ medium, phosphoserine was probably transported into the cell without dephosphorylation.

It has been suggested that the growth inhibition of micro-organisms unable to synthesize vitamin B6 by $4^{\prime}$-deoxypyridoxine is due to the formation of a phosphorylated derivative which competitively inhibits the binding of pyridoxal 5 -phosphate to various apoenzymes (Umbreit \& Waddell, 1949). Our results extend these findings to include $E$. coli and to an inhibition of pyridoxine transport. The action of $4^{\prime}$-pyridoxine on $E$. coli is more complex than simple inhibition, however, because under certain conditions it can stimulate the growth of vitamin B6 auxotrophs. This stimulatory effect at certain concentrations might be explained as follows: 4'-deoxypyridoxine inhibits growth of strain BL-1, but when pyridoxal is limiting, a mechanism is available to convert the analogue into pyridoxal and pyridoxal $5^{\prime}$-phosphate. Although this mechanism becomes operative at a certain threshold concentration of $4^{\prime}$-deoxypyridoxine, there is a saturation level above which further conversion of 4'-deoxypyridoxine is no longer possible. Interestingly, in Bacillus subtilis, 4'deoxypyridoxine $5^{\prime}$-phosphate is apparently an intermediate in vitamin B6 biosynthesis (Pflug \& Lingens, 1978).

We are grateful to Mrs T. Beetham for technical help. R.C.H. thanks the Science Research Council for a Studentship. 


\section{REFERENCES}

Davis, B. D. \& Mingioli, E. S. (1950). Mutants of Escherichia coli requiring methionine or vitamin B12. Journal of Bacteriology 60, 17-28.

DEMPSEY, W. B. (1966). Synthesis of pyridoxine by a pyridoxal auxotroph of Escherichia coli. Journal of Bacteriology 92, 333-337.

Dempsey, W. B. (1969). Evidence that 3-phosphoserine may be a precursor of vitamin B6 in Escherichia coli. Biochemical and Biophysical Research Communications 37, 89-93.

Hill, R. E., Horsewood, P. \& Spenser, I. D. (1975). Biosynthesis of vitamin B6. Incorporation of glycolaldehyde into pyridoxal. Journal of the Chemical Society, Perkin I 1622-1627.

HockNey, R. C. \& SCOTt, T. A. (1979). The isolation and characterization of three types of vitamin B6 auxotrophs of Escherichia coli K12. Journal of General Microbiology 110, 275-283.

Pflug, W. \& Lingens, F. (1978). Vitamin-B6Biosynthese in Bacillus subtilis. Hoppe-Seyler's Zeitschrift für physiologische Chemie 359, 559. 570.
Picton, C. (1975). Studies of the metabolism of 3-hydroxy-2,4,5-trihydroxymethylpyridine. Ph.D. thesis, University of Leeds.

Rabinowitz, J. C. \& SNeLl, E. E. (1953). Vitamin B6 antagonists and growth of microorganisms. I. 4-Desoxypyridoxine. Archives of Biochemistry and Biophysics 43, 399-407.

Schroer, R. A. \& Frieden, E. H. (1973). Pyridoxal biosynthesis by Saccharomyces fragilis. Proceedings of the Society for Experimental Biology and Medicine 142, 369-373.

ScotT, T. A. \& Picton, C. (1976). The conversion of 3-hydroxy-2,4,5-trihydroxymethyl pyridine into pyridoxine by Kloeckera apiculata. Biochemical Journal 154, 35-41.

Tiselius, H. G. (1972). A chromatographic separation of the different forms of vitamin B6. Clinica chimica acta 40, 319-324.

Umbreit, W. W. \& Waddell, J. C. (1949). Mode of action of desoxypyridoxine. Proceedings of the Society for Experimental Biology and Medicine 70, 293-299. 